\title{
Terahertz hyperspectral imaging of lab-prepared versus commercial paracetamol tablets and potential applications
}

D. T. Nguyen ${ }^{1}$, F. Dortu ${ }^{1}$ A. Dispas², Ph. Hubert², E. Ziemons², Y. Hernandez ${ }^{1}$

${ }^{1}$ Applied Photonics Department, Multitel A.S.B.L, 7000 Mons, Belgium

2University of Liege (ULiege), CIRM, VibraSante Hub, Laboratory of Pharmaceutical Analytical Chemistry, B-4000 Liège, Belgium

\section{INTRODUCTION}

- Analytical techniques in pharmaceutical sciences are broad and intensively used.

$>$ Each method has its own advantages and drawbacks, therefore it can only be applied in several applications.

$\checkmark$ Vibrational spectroscopy is one of the most suitable analytical technique for chemical, physical, biological and pharmaceutical analysis as it can be fast, robust and non-destructively testing of the samples.

$>\mathrm{THz}$ hyperspectral imaging using time-domain spectroscopy technique has been applied to image a commercial packaging of paracetamol tablets, showing the ability to penetrate through both cardboard of the box and plastic cover of the blister pack.

$>$ To the best of our knowledge, this is the first time such experiment has been carried out.

\section{EXPERIMENTAL SETUP}

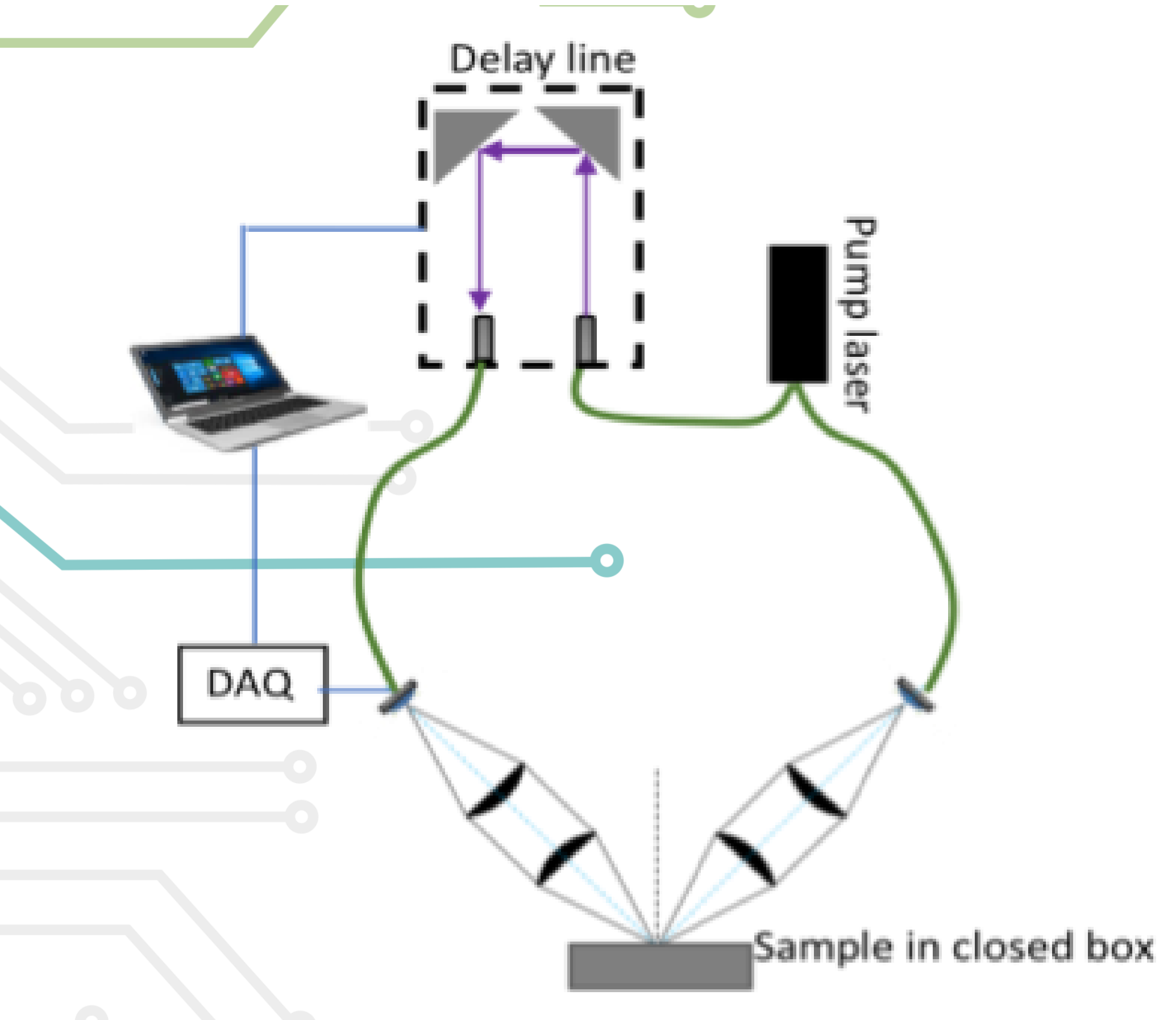

(a)

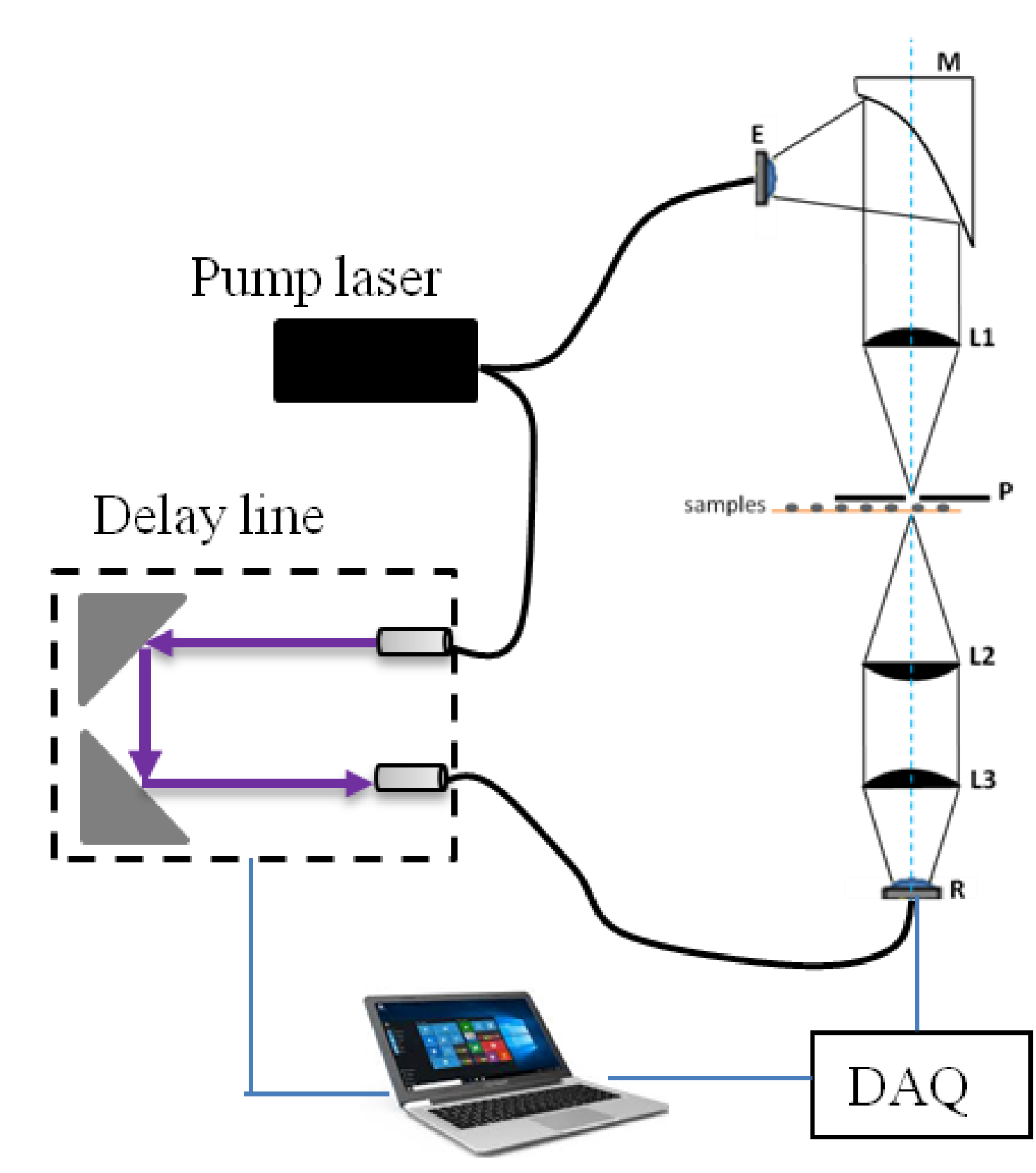

(b)

Figure1. Schemes of the measuring system in RESULTS reflection mode (a), and in transmission mode (b).

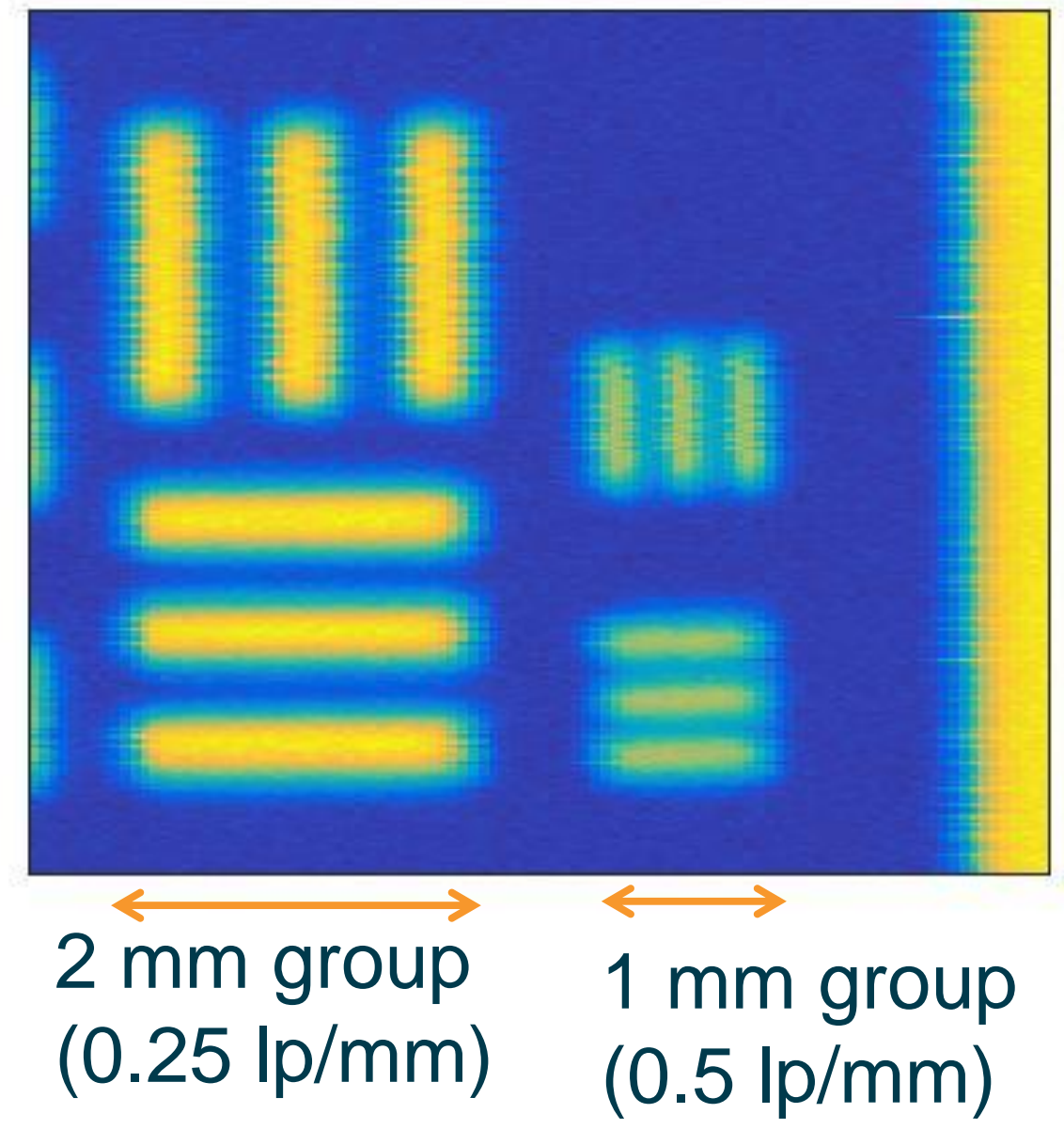

Figure 2. THz peak-to-peak transmission image of a homemade resolution target at $0.25 \mathrm{lp} / \mathrm{mm}$ and $0.5 \mathrm{lp} / \mathrm{mm}$ groups

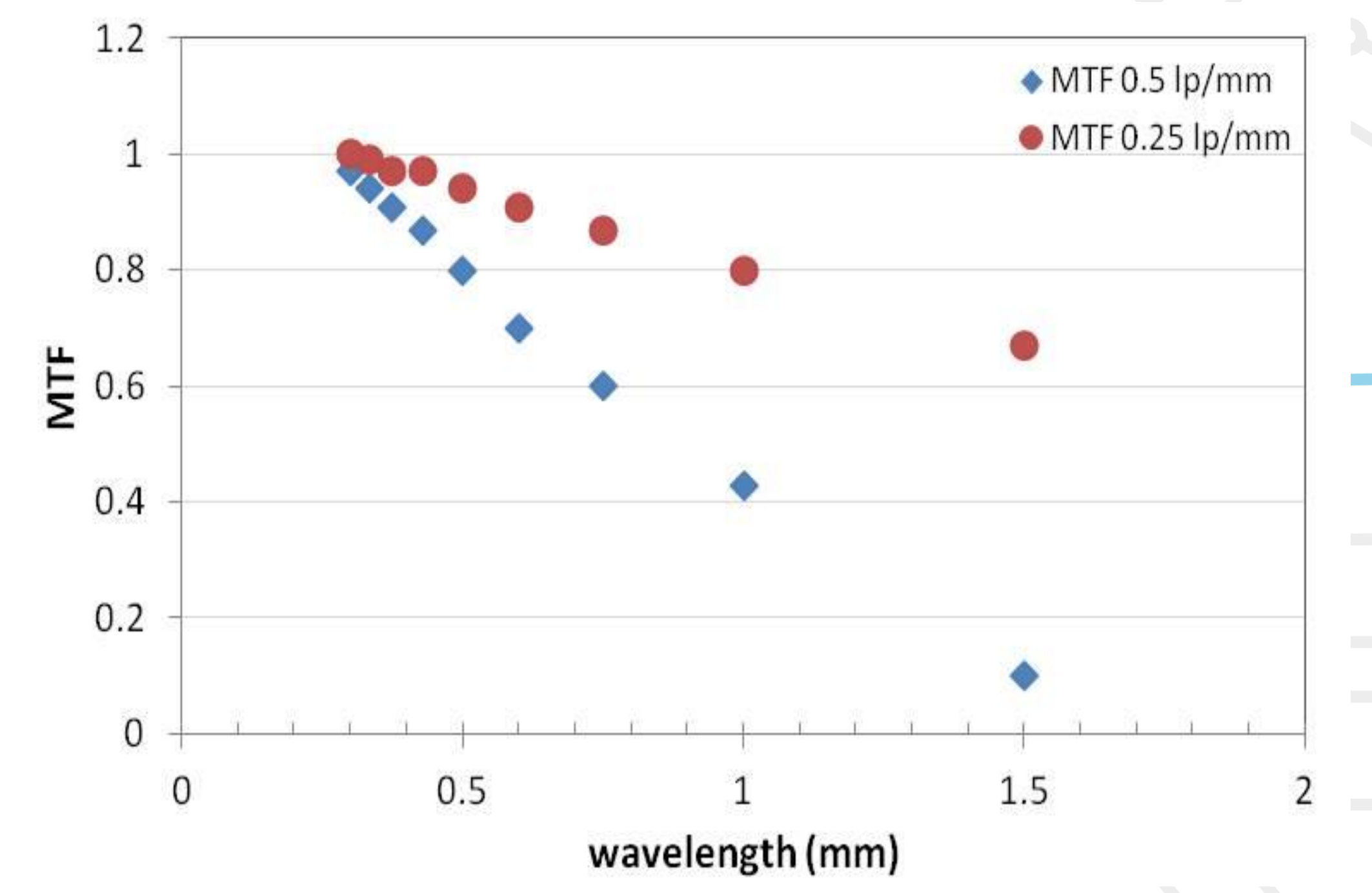

Figure 3. Modulation transfer function of the resolution group: $1 \mathrm{~mm}$ (blue squared, 0.5 $\mathrm{lp} / \mathrm{mm}$ ) and $2 \mathrm{~mm}$ (red round, $0.25 \mathrm{lp} / \mathrm{mm}$ ).

$>$ The lab-prepared paracetamol tablets contained different API concentrations from 80 to $120 \%$ of the nominal value and are noted as: API80, API100, and API120 for the \% in weight of API presented in the sample, and placebo.

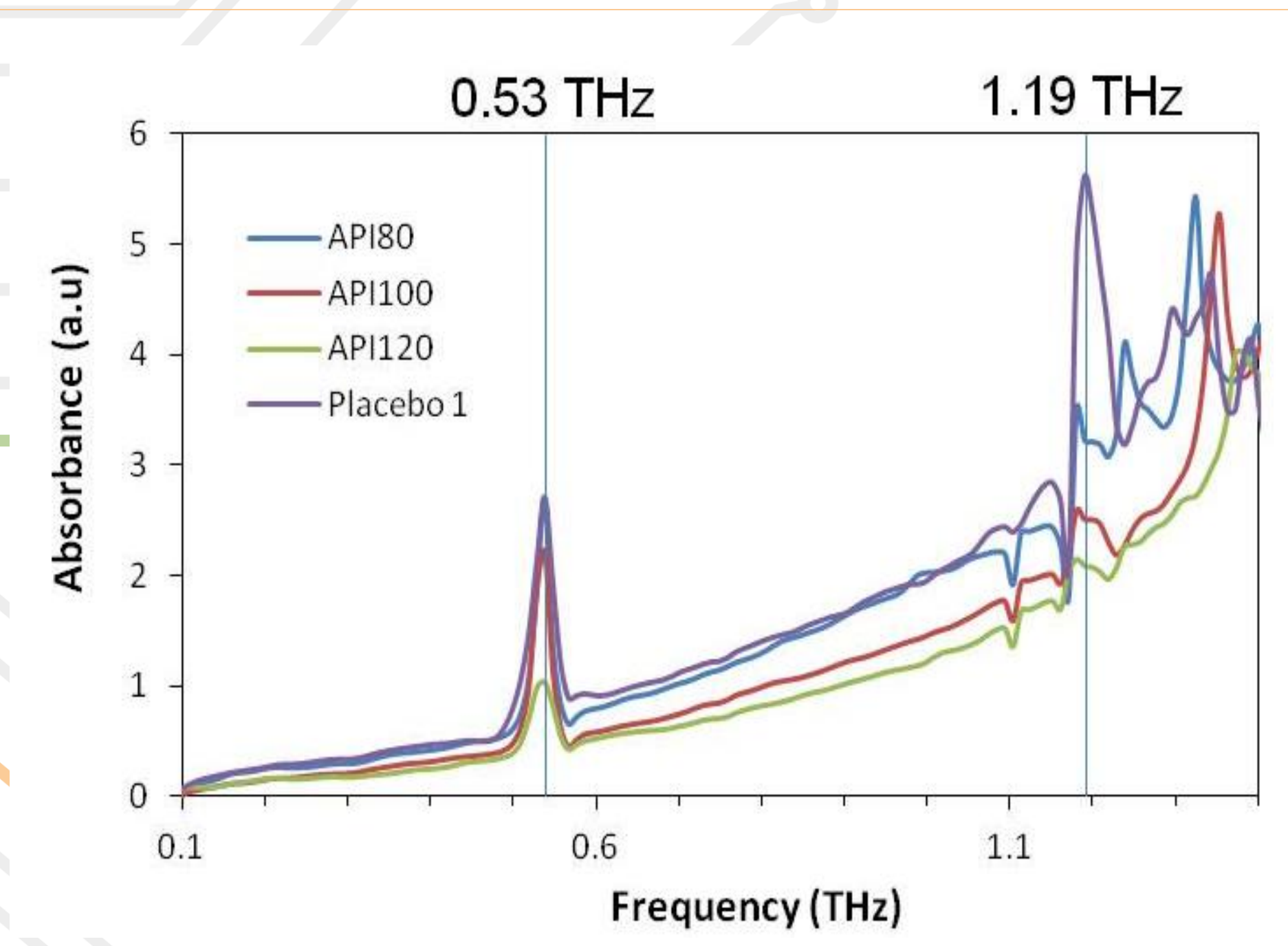

Figure 4. $\mathrm{THz}$ absorbance of the labprepared paracetamol tablets and placebo.

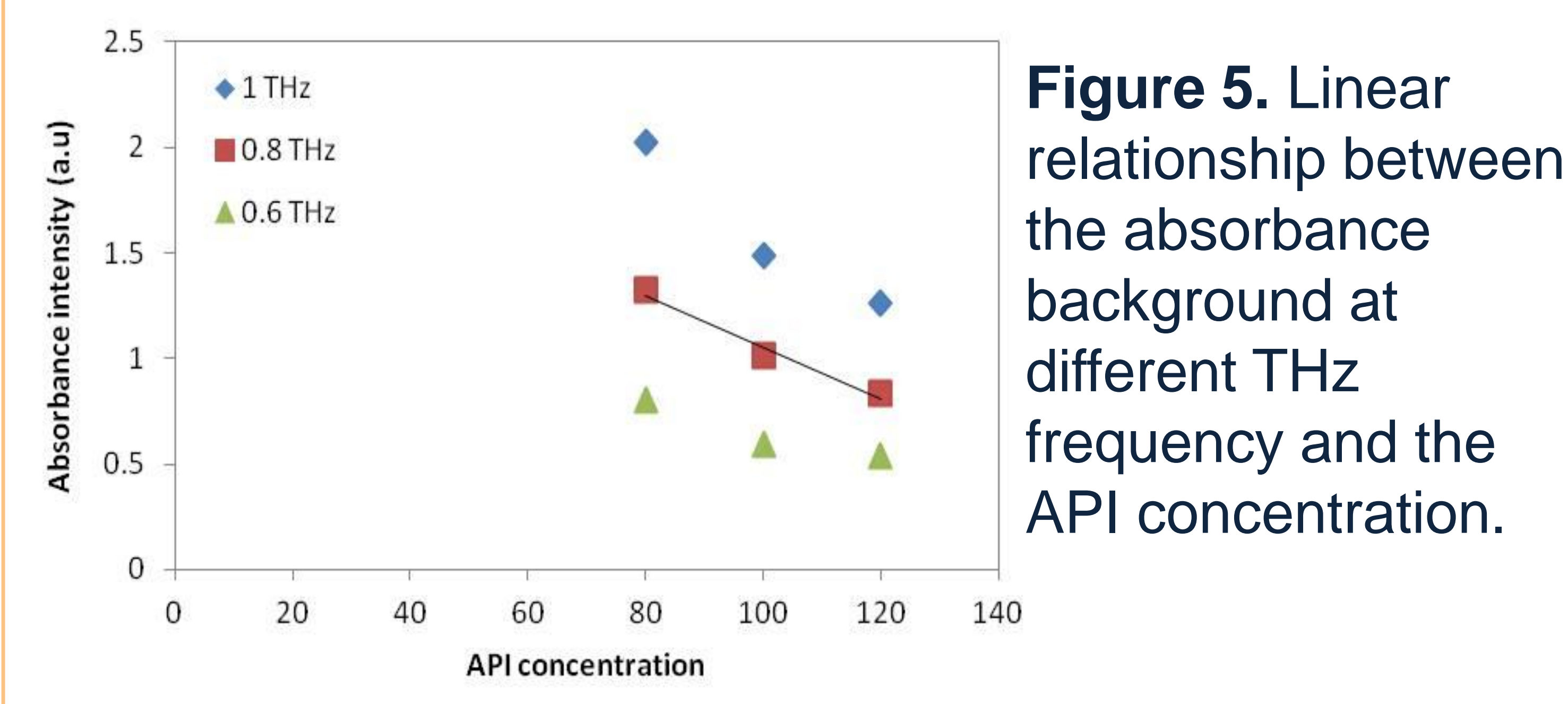

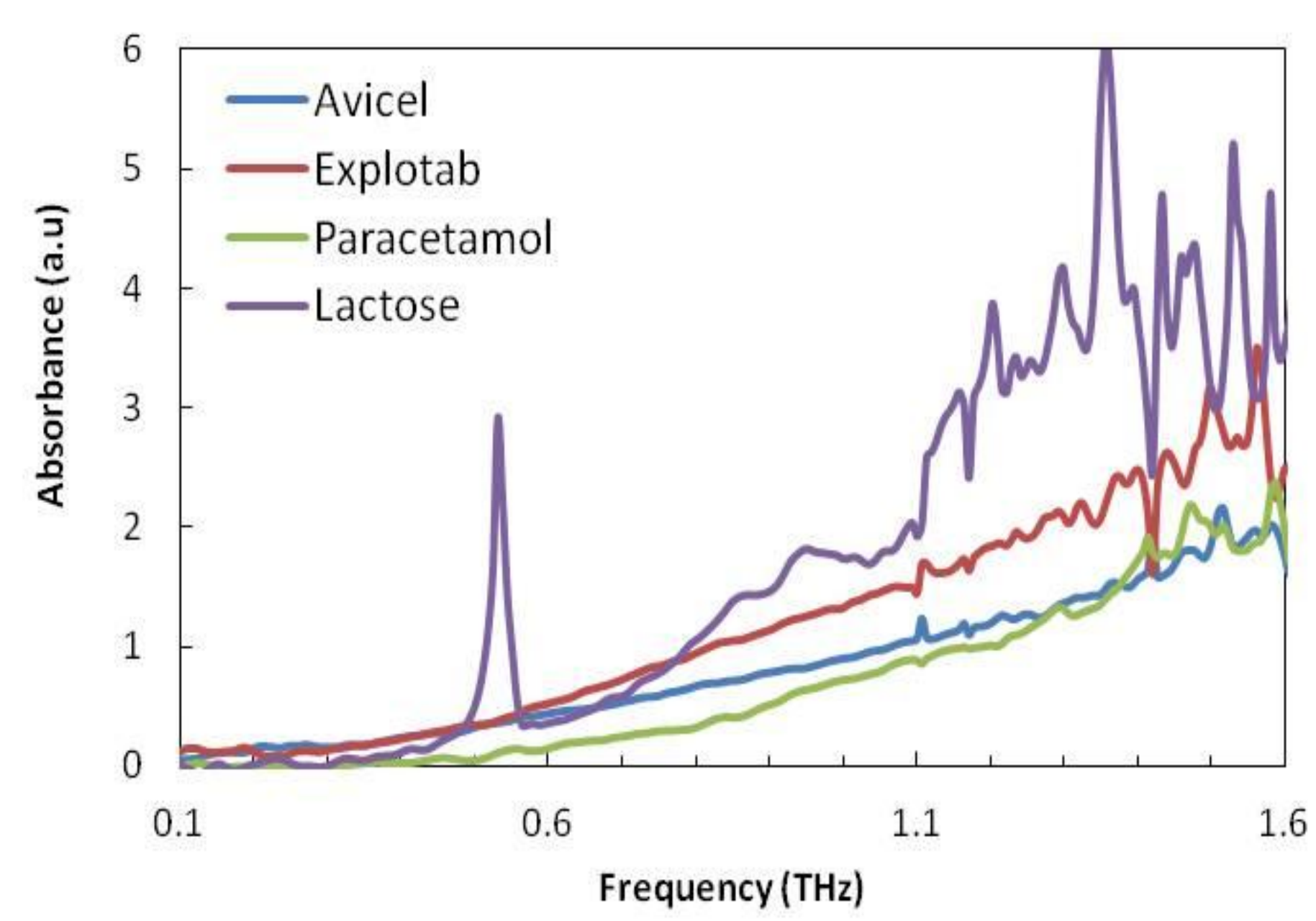

Figure 6. THz absorption spectrum of each compound of in a lab-prepared tablet.
Figure 7. Reconstructed peak-topeak scanning image of a commercial paracetamol product covered inside its cardboard and blister packaging.

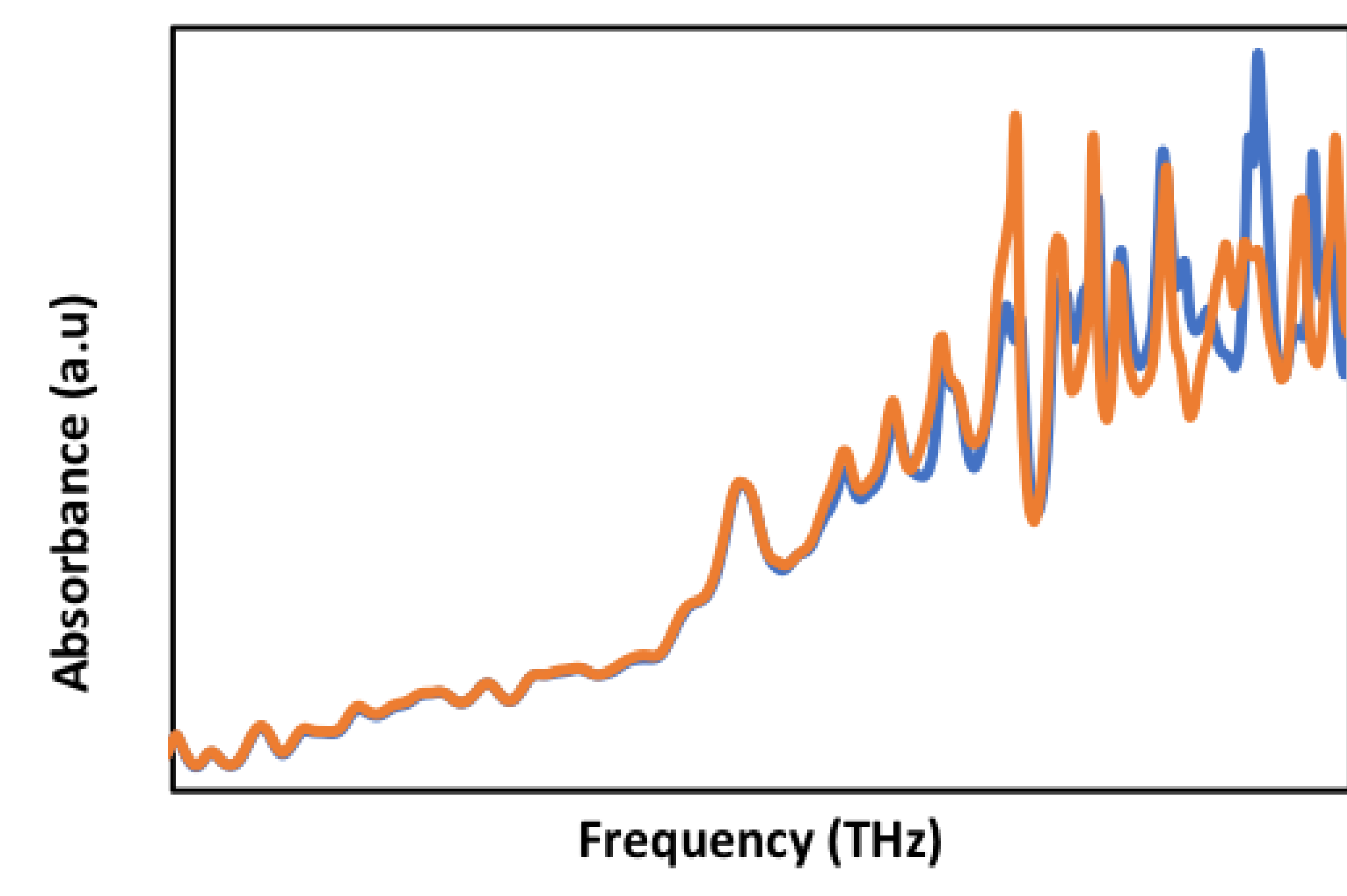

Figure 8. Absorption spectra of commercial paracetamol tablets presented inside the cardboard box and the blister.

PLUS HAUT

ET PLUS PROCHE

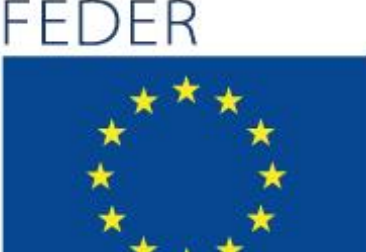
(1)

\section{CONCLUSION}

We have performed a range of measurements on lab-prepared and commercial paracetamol tablets. Terahertz hyperspectral imaging using time-domain spectroscopy technique has been applied to demonstrate the ability to penetrate through the packaging covers. A Tinear relationship between a related ingredient and their absorbance in $\mathrm{THz}$ range were observed. This work opens up a possibility of using THz-TDS to non-destructively control the quality of pharmaceutical products in commercial packaging.

This work was conducted under the projects PHARE and TERA4ALL. We acknowledge the ERDF and the Federation of the Walloon region of Belgium for funding the projects.

\section{Multitel Rue elere et mare cure 2 Parc Scientifique Initialis \\ +32(0)65 342732 info@multitel.be \\ www.multitel.be \\ If in $y$}

